\title{
ZHOU Zhimin
}

\section{How to measure brand relationship quality?}

(C) Higher Education Press and Springer-Verlag 2007

\begin{abstract}
The aim of this research is to develop a new evaluation approach based on a brand relationship index model (BRI model), which includes a three stage study on the indicator system; indicator weight; and indicator integration. Based on brand identity theory and interpersonal relationship theory, four-brand relationship participants and three-brand relationship natures are put forward to make up a hypothesis of twelve-dimension brand relationships. Through a series of empirical studies based on exploratory factor analysis (EFA) and confirmatory factor analysis (CFA), a five-dimension structure of brand relationships is obtained, which is the basis of the indicator system. Indicator weight is calculated by the normalization of path coefficients derived from a second order factor analysis of the five dimensions. Indicator integration is based on the Weighted Sum method. Based on these three ingredients, the brand relationship index (BRI) model is developed. According to analysis of data on ten mobile phone brands, the BRI model is tested.
\end{abstract}

Keywords brand relationships, relationship quality, relationship evaluation, index model

\section{Introduction}

Brand and consumer relationships (abbr. brand relationships) have been the latest research focus in brand research (Lu and Zhou, 2003). In 1992, Blackston compared brand relationships to interpersonal relationships and established a new research direction by pointing out that intimate, permanent, stable relationships can form from the interaction between a brand and its consumers. Some brand

Translated from Yingxiao Kexue Xuebao 营销科学学报 (Journal of Marketing Science), 2006, 2(2): 24-40

ZHOU Zhimin $(\bowtie)$

College of Management, Shenzhen University, Shenzhen 518060, China

E-mail:mnizzm@szu.edu.cn 
innovation researchers (e.g. Fournier, 1998; Aggarwal, 2004; Aaker, 2005) paid a great deal of attention to the new construct because it reflected the research trend in relationship marketing and brand equity.

In the initial brand relationships theory, brand and consumer were treated as two interactive participants in the relationship (Blackston, 1992). Based on this opinion, the latter scholars added company, consumer and product into the relationship model, which resulted in the multi-facet brand relationship interaction model (Fournier, 2001) and the brand community model (McAlexander et al, 2002). The initial concept is defined as a brand relationship in a narrow sense, and the latter concept as a brand relationship in a broad one. As an analogous concept with a broad brand relationship, a customer relationship means the relationship between enterprise staff and customers, whereas a broad brand relationship means the relationship between brand association and customers. Accordingly, the concept of a customer relationship is suitable for describing service industries, but the concept of a brand relationship is for consumption industries. However, there is no an essential difference between the two concepts, because brand relationship is an extension of and a form of customer relationship (Barnes, 2001).

As one of the most important assets in enterprises, brand relationship equity has been attached with great importance by scholars and practitioners. Duncan and Moriarty (2000) thought that the unit to for calculating corporate equity is brand relationships instead of goods. Quinn (1992) pointed out that managers should describe and measure a business before understanding and managing. Harrington also suggested that quantification was the first step in management. However, enterprisers mainly focus on how to build up relationships but make little endeavor to understand relationship quality at present (Barnes, 2002). There is also a lack evaluation on brand relationship strength in current research ( $\mathrm{Lu}$, 2002). Therefore, the aim of this article is to put forward a new method to evaluate brand relationships named brand relationship index model (BRI model).

\section{Literature review}

In prior literature, the methods of brand relationship evaluation can be sorted into the value methods and the indicator ones. The value methods focus on the financial output of brand relationships, however, the indicator ones on the ingredients. The differences between both methods exist in research contents, research thoughts, manifestation and applications (Zhou, 2005). There are several research findings in the literature of the value methods, such as the customer value assessment system (Reichheld, 1996), and the customer life-time value evaluation (Rust et al., 2000). In contrast, the quantity of the indicator methods literature is numerous. It is because the value research is mature in thoughts and 
methods, but not all researchers agree on the components of brand relationships. Further research on indicator is necessary. Some typical indicator literatures are exhibited as below.

The Two Factor theory. Blackston (1992) discovered that the successful brand relationships consisted of two factors: trust and satisfaction. Trust is influenced by risk, credibility and intimacy, whereas satisfaction is influenced by initiative and supportiveness. However, it is not perfect that only two factors are used to measure brand relationships. For example, brand familiarity has been neglected in his theory.

The Three Indicator theory. Markinor Market Research Co. in South Africa has developed the brand relationship score (BRS) to launch "Markinor Top Brands Survey” from 1992, which is summarized by three indicators, namely, awareness, trust and loyalty. It is not perfect either, because of the neglect of satisfaction. And another defect is that every indicator is measured by only one item. It is not enough. For example, in a lot of researches, brand trust is measured by several items (Delgado-Ballester, 2002). ${ }^{1}$

The Six Element theory. Fournier (1998) measured brand relationship strength, stability and constancy through a new construct of the brand relationship quality (BRQ), which contained six elements: love and passion, self-connection, interdependence, commitment, intimacy, and brand participant quality. These six parts can be combined into three bigger parts, which are affective and social attachments, behavioral ties, supportively cognitive beliefs. In 2001, Aaker, Fournier and Brasel launched an empirical research to testify six parts of BRQ. All Cronbach's $\alpha$ exceeds 0.9, which means that there may be overlaps between items to some extent. On the other hand, an integrated quantitative model was not advanced, which did not make managers to grasp the comprehensive condition of brand relationships simply.

The Eight Indicator theory. Duncan and Moriarty (1999) put forward eight indicators to evaluate brand relationships from the perspective of practice, which consists of awareness, credibility, consistency, contact, responses, passion, affinity and fancy. The indicator system is enumerated by virtue of the researchers' experience, not a series of theories and empirical studies, which may influence completeness and stability of indicators.

The five-star model. Aaker (1991) brought forward the famous Five-star model of brand equity from the perspective of cognition, which was composed of brand awareness, quality perception, brand associations, brand loyalty and other equities. The existence of the former four components was testified by a latter empirical research (Yoo and Donthu, 2001). However, some important constructs, such as satisfaction and trust, are not embodied in these four components.

\footnotetext{
${ }^{1}$ Delgado-Ballester E (2002). Development and validation of a brand trust scale. www.csom. umn.edu/Images/ACF63F.pdf
} 
Customer relationship index. Barnes (2001) created a customer relationship index according to the interpersonal relationship measures. The index included information about communications between customer and company (such as purchase frequency, relationship constancy, customer expenditure ratio), important customer relationship indicators (such as emotion), indicators of relationship quality (intimacy, possibility of relationship constancy, possibility of word-of-mouth effect), customer satisfaction, customer's feeling of value, and so on. These indicators were rather completed, but Barnes did not bring forward a formula to calculate weights of indicators, which could not summarize integrated condition of brand relationships. On the other hand, most of these indicators only apply to service industries (e.g. beauty parlor) instead of consumer goods industries (e.g. beverage).

Other literature on indicator evaluation. Keller (2001) thought that brand relationships can be usefully characterized in terms of two dimensions of intensity and activity. Gallup Co. developed five dimensions of brand relationships, which are loyalty, confidence, reliability, pride and passion. Both researches put stress on affective part of relationship, but neglect cognitive part.

Above all, there are four defects existing in the current researches. First, researchers pay more attention to affection but neglect cognition, which influences completeness of indicators quantity. Second, most studies of indicators were based on researchers' experience rather than empirical studies, which influences reliability of indicators. Third, most researchers studied the relationships between brand and consumer only, but neglect the relationships between company, product and consumers. Fourth, in most researches, indicators were not combined into a total score without weights, so the integrated condition cannot be comprehended by managers. In order to solve these problems, this research will try to put forward a new index model to measure comprehensive brand relationships strength in a broad sense. In the process, indicator system, indicator weight and indicator integration are three necessary branch studies. Specially, the study of indicator system is the most important. Brand relationship structure in a broad sense is essentially the basis of brand relationship indicator system. Through factor analysis, brand relationships structure is decomposed. Every component corresponds with each indicator for evaluation. Once brand relationship indicator system is achieved, the weight and integration of indicators will be also achieved according to the relationships between indicators. Therefore, the key step of the research is to analyze the structure of brand relationships in a broad sense.

\section{The hypothesised of brand relationship structure}

In the prior researches, the basic research paradigm of brand relationships is the cross-disciplinary perspective from which brand relationships are looked 
as interpersonal relationships (Fournier, 1998; Blackston, 1992; Barnes, 1999). According to some definitions of interpersonal relationship in the field of social psychology, all relationships contain two parts: one is the participant of relationship, the other is the nature of relationship. In another word, brand relationships in a broad sense consist of brand relationship participant and nature. Brand relationship participant is a role in relationships, and relationship nature is a category of brand relationships in the essence.

\subsection{Brand relationship participant}

Most researchers took brand and consumer as relationship participants (e.g. Blackston, 1992, 1995). However, from a broader perspective, brand can be identified through several ways and in fact can be divided into several different components. Brand is not only a distinctive symbol with added value, but also a cluster of perception which includes all customer opinions on the brand's associations (Levy, 1978; Reynolds and Gutman, 1984). Thus, brand relationship participants are consisted of several parts besides brand itself.

Aaker (1998) pointed out that brand manager should think brand as a product, enterprise, person and symbol to build the framework of brand identity. The four-subject brand theory provided theoretical basis for the generalization of brand construct.

Fournier (2001) advised studying brand relationships from a broader perspective. She divided consumer-brand relationships into four parts: the consumerproduct connection, the consumer-brand connection, the consumer-consumer connection and the consumer-company connection. McAlexander et al. (2002) testified four relationships in an empirical study on brand community.

Cross and Smith (1998) thought that there were five phases in the formation process of brand relationships, which were cognition, agreement, connection, community and support. The process included the contacts between consumer and brand, product, company, and other consumers.

Above all, brand can be divided into four subjects in a broad sense, namely, product, brand, marketer and consumer.

\subsection{Brand relationship nature}

The study of brand relationship nature refers to some research findings in the research field of interpersonal relationship structure. The current main opinion is that interpersonal relationship is composed of cognition, affection and behavior (Zhang, 1996; Le, 2002). Similarly, the nature of the brand relationships can be thought as containing these three components: cognition, as the basis of brand relationship, is the consumer's familiarity with the brand; affection, as the core of the brand relationship, is consumer's feeling of brand; conation, as the 
representation of brand relationship, is consumer's commitment to brand. In this research, conation replaces behavior, as the former is a more realistic reflection of relationships. The hypothesis of three components is in conformity with other research findings (Markinor, 2001; Fournier, 1998; Shi and Wang, 2005).

\subsection{The hypothesised of brand relationship structure in a broad sense}

Relationship participants and natures are combined to a matrix of brand relationship structure in a broad sense (see Table 1). The matrix shows that all possible brand relationships are composed of different natures between different participants. It is more comprehensive than those researches mentioned previously.

Table 1 The matrix of brand relationship construct in a broad sense

\begin{tabular}{lccc}
\hline Relationship participant & \multicolumn{3}{c}{ Relationship nature } \\
\cline { 2 - 4 } & Cognition & Affection & Conation \\
\hline Consumer-brand & 1 & 5 & 9 \\
Consumer-product & 2 & 6 & 10 \\
Consumer-marketer & 3 & 7 & 11 \\
Consumer-consumer & 4 & 8 & 12 \\
\hline
\end{tabular}

Twelve relationships in the matrix can be seen as dimensions of brand relationships in broad sense, which are used as the theoretical framework to develop scale dimensions and items. The meanings of these dimensions are displayed below.

(1) The cognition relationship between consumer and brand is the consumer's familiarity with and memory of brand symbol or meaning.

(2) The cognition relationship between consumer and product is the consumer's familiarity with and memory of product and service attributes.

(3) The cognition relationship between consumer and marketer is the consumer's familiarity with and memory of brand organization attributes.

(4) The cognition relationship between consumer and consumer is the consumer's familiarity with and memory of other consumers of the brand.

(5) The affection relationship between consumer and brand is the consumer's feeling of brand symbol and meaning.

(6) The affection relationship between consumer and product is the consumer's feeling of product and service attributes.

(7) The affection relationship between consumer and marketer is the consumer's preference for and trust in brand organization.

(8) The affection relationship between consumer and consumer is the consumer's feeling for and evaluation of typical consumers of the brand. 
(9) The conation relationship between consumer and brand is the consumer's long-term commitment or intention of action towards brand.

(10) The conation relationship between consumer and product is the consumer's will to make contact with brand product.

(11) The conation relationship between consumer and marketer is the consumer's commitment or other communication intention towards brand marketer.

(12) The conation relationship between consumer and consumer is the consumer's will to communicate with other consumers of the brand.

\section{Research Method}

\subsection{Item development}

According to Churchill (1979), Gerbing and Anderson (1988), it will take three steps to develop items. The first step is to review the important literature in recent years. The second step is to create some items based on the related theoretical constructs. The third step is experts' opinion. Six PhD candidates and four MA students in China Marketing Research Center of Sun Yet-sen University were invited to complete and modify these items. As a result, there are forty-five items in the original scale.

\subsection{Selection of industries and brands}

All brands mentioned in all tested industries will be mixed as a virtual brand to research its relationship structure (e.g. Yoo and Donthu, 2001). The criteria for selecting tested industries are representativeness and popularity. Representativeness means that tested industries must cover all kinds of categories of products and services. Popularity means those tested industries which are patronized most often by samples often patronage. The researchers looked into the Annual of IMI Product and Lifestyle (2002-2003) edited by Advertisement Department in Beijing Broadcast Institute. At last, twenty-four industries which include twelve product industries and twelve service industries are selected (Table 2). Twelve product industries cover convenience products, preference products, shopping products and specialty products, and twelve service industries cover four types assorted according to the relationships between enterprises and customers (Lovelock, 1983). Twenty-four industries contain main consumer categories, such as household, food, electrical appliance, communication, traffic, education, entertainment, financial service, and insurance. The market coverage of most industries is above $50 \%$. Tested brands are decided by subjects themselves, which can ensure their familiarity. 
Table 224 Industries in 12 questionnaires

\begin{tabular}{cccccc}
\hline 1 & 2 & 3 & 4 & 5 & 6 \\
\hline $\begin{array}{c}\text { Fast food; } \\
\text { mobile } \\
\text { telephone }\end{array}$ & $\begin{array}{c}\text { Website; } \\
\text { shampoo }\end{array}$ & $\begin{array}{c}\text { Toothpaste; } \\
\text { mobile } \\
\text { communication }\end{array}$ & $\begin{array}{c}\text { Washing } \\
\text { powder; } \\
\text { book shop }\end{array}$ & $\begin{array}{c}\text { Bank; } \\
\text { cola }\end{array}$ & $\begin{array}{c}\text { Color TV; } \\
\text { supermarket }\end{array}$ \\
\hline 7 & 8 & 9 & 10 & 11 & 12 \\
\hline $\begin{array}{c}\text { Portable } \\
\text { computer; } \\
\text { hotel }\end{array}$ & $\begin{array}{c}\text { Refrigerator; } \\
\text { airline }\end{array}$ & $\begin{array}{c}\text { Washing } \\
\text { machine; } \\
\text { TV station }\end{array}$ & $\begin{array}{c}\text { Film; } \\
\text { express }\end{array}$ & $\begin{array}{c}\text { Commercial } \\
\text { housing; } \\
\text { insurance }\end{array}$ & $\begin{array}{c}\text { University; } \\
\text { instant } \\
\text { noodle }\end{array}$ \\
\hline
\end{tabular}

\subsection{Data collection}

The questionnaire comprised four parts. The first part contains a question that "my favorite cola is Cocacola", which is used for mean analysis. The second one contains the initial scale of brand relationships in a broad sense. The third one contains two questions that "I use brand $X$ very often" and "I will support brand $X$ for a long time", which are used to measure convergent validity and predict validity. The fourth one contains some questions about demography, such as gender, age, education, city, income, and vocation.

The sampling method is a quota one, which consists of two phases. In phase I, 1,800 questionnaires were sent out and 1,504 were received, among which are 1,362 valid samples. Valid recovery rate is $76 \%$. In phase II, samples will be selected further by the principle of dispersal which will improve the representativeness of sample. The sample size of each industry is decided by the ratio of market coverage of industries. Total sample size should exceed 450 in terms of Nunnally's advice. At last, 760 samples are confirmed valid from 1,362 ones. The sample structure is shown in Table 3.

Table 3 Descriptions of valid sample structure

\begin{tabular}{ll}
\hline Variable & \multicolumn{1}{c}{ Sample structure } \\
\hline $\begin{array}{l}\text { Gender } \\
\text { Age }\end{array}$ & Male, 441; female, 319 \\
& Less than 20 years old, 13; 20-24 years old, 298; 25-29 years old, \\
& 286; 30-39 years old, 126; 40-49 years old, 26; more than \\
City & G0 years old, 11 \\
& Guangzhou, 277; Beijing, 95; Shanghai, 68; Shenzhen, 51; Xiamen, \\
& 16; Fuzhou, 57; Nanchang, 38; Nanjing, 26; Weihai, 52; \\
& Other cities, 80 \\
Education & Senior high school or secondary school, 54; junior college, 175; \\
& undergraduate, 368; postgraduate, 163 \\
Vocation & Government or public institution, 125; enterprise, 340; student, 246; \\
& self-employed individual, 23; other vocations, 26 \\
Monthly income & Less than ¥ 1500, 340; ¥ 1500-2999, 199; ¥ 3000-4499, 117; \\
& $¥$ 4500-5999, 54; $¥ 6000-7499,31 ;$ more than ¥ 7500, 19 \\
\hline
\end{tabular}


All data are testified by analysis of variance (ANOVA). Null hypothesis is confirmed (sig. $=0.636>0.05$ ), which means all samples come from one entity. Therefore, all brands mentioned can be mixed in the research.

\subsection{Item purification}

There are four criteria of item purification in the research. First, if item-total correlation is lower than 0.4 and Cronbach's $\alpha$ will increase after the item is cancelled, the item should be cancelled (e.g. Yoo and Donthu, 2001; Aaker et al., 2001; McAlexander et al., 2002). Second, if rotated factor loading is lower than 0.4 , the item should be cancelled (Nunnally, 1978). Third, if an item's factor loadings on two factors are higher than 0.4 at the same time, the item should be cancelled (Nunnally, 1978). Fourth, if both factor loadings of an item on factor A and $\mathrm{B}$ are higher than critical value, the item should be cancelled (e.g. Zhang, 2001). But if factor A and B are combined after canceling the item, the item should not be cancelled. According to these four criteria, 16 items are cancelled from 45 ones, so the rest 29 ones make up of a formal scale for next analysis (see Appendix).

\subsection{Data quality}

Guttman Split-half is 0.8492, and Cronbach's $\alpha$ of twenty-nine items is 0.9352, which means data reliability is perfect. Content validity is ensured by experts' minor modifications. Item to total coefficients of twenty-nine items exceed 0.4, which means construct validity is fine. As mentioned above, both questions that "I use brand X very often" and "I would like to support brand X for a long time" are designed for testing convergence validity and predict validity. Pearson's correlation coefficients between the sum of five dimensions' scores and both questions' scores are respectively 0.625 and $0.660(p=0.00<0.01$, 2-tailed), which indicates that convergence validity and predict validity are fine.

\subsection{Exploratory factor analysis}

Twenty-nine items are analyzed by factor analysis method in SPSS11.0. KMO is 0.945 and the significance level of Bartlett's test of sphericity is lower than 0.05. The eigenvalues of the first five factors are higher than 1 , the scree plot shows that the difference between the first five and the rest factors is big. The cumulative extraction sum of squared loadings is 58.149\%. Qualitatively, there may be interrelationships between factors, so the analysis approach of Promax is chosen (Lu, 2000). As shown by the result, twenty-nine items are smoothly converged into five factors and factor loading of each item is higher than 0.4, which means the existence of five factors is affirmed (see Table 4). 
Table 4 Pattern matrix

\begin{tabular}{|c|c|c|c|c|c|}
\hline \multirow{2}{*}{ Serial number of item } & \multicolumn{5}{|c|}{ Factor } \\
\hline & Factor 1 & Factor 2 & Factor 3 & Factor 4 & Factor 5 \\
\hline I1 & 0.651 & & & & \\
\hline$I 2$ & 0.653 & & & & \\
\hline I3 & 0.719 & & & & \\
\hline I4 & 0.779 & & & & \\
\hline$I 5$ & 0.913 & & & & \\
\hline I6 & 0.687 & & & & \\
\hline$I 7$ & 0.508 & & & & \\
\hline 18 & 0.752 & & & & \\
\hline 19 & 0.724 & & & & \\
\hline$I 10$ & 0.527 & & & & \\
\hline$I 11$ & 0.523 & & & & \\
\hline$I 12$ & & 0.545 & & & \\
\hline$I 13$ & & 0.558 & & & \\
\hline$I 14$ & & 0.722 & & & \\
\hline$I 15$ & & 0.438 & & & \\
\hline$I 16$ & & 0.819 & & & \\
\hline$I 17$ & & 0.750 & & & \\
\hline$I 18$ & & 0.888 & & & \\
\hline$I 19$ & & & 0.535 & & \\
\hline$I 20$ & & & 0.844 & & \\
\hline$I 21$ & & & 0.863 & & \\
\hline$I 22$ & & & 0.712 & & \\
\hline$I 23$ & & & 0.630 & & \\
\hline$I 24$ & & & & 0.405 & \\
\hline$I 25$ & & & & 0.790 & \\
\hline$I 26$ & & & & 0.889 & \\
\hline$I 27$ & & & & 0.761 & \\
\hline$I 28$ & & & & & 0.889 \\
\hline$I 29$ & & & & & 0.870 \\
\hline
\end{tabular}

\subsection{Confirmatory factor analysis}

In order to confirm the stability of structure in Table 4, a CFA was made by LISREL8.20. Twenty-nine items are treated as observing variables $(x)$ and five factors as potential ones $(\xi)$. Two kinds of variables can constitute a path model. According to some fit indices of the model, $\chi^{2} / \mathrm{df}=3.641, R M S E A=0.059$, $C F I=0.91, N N F I=0.90$, which indicate high degree of fitting. Path coefficients and $t$ values are shown in Table 5 . All $t$ values are larger than 2 , which means the existence and significance of the relationships between five factors and twenty-nine items. 
Table 5 Path relationships

\begin{tabular}{|c|c|c|c|c|c|}
\hline Path & Path coefficient & $t$ value & Path & Path coefficient & $t$ value \\
\hline$\xi_{1}-X_{1}$ & 0.79 & 22.06 & $\xi_{3}-X_{21}$ & 0.63 & 15.10 \\
\hline$\xi_{1}-x_{2}$ & 0.78 & 21.00 & $\xi_{3}-X_{22}$ & 0.73 & 17.20 \\
\hline$\xi_{1}-x_{3}$ & 0.85 & 23.36 & $\xi_{3}-X_{23}$ & 0.70 & 17.91 \\
\hline$\xi_{1}-\chi_{4}$ & 0.66 & 19.03 & $\xi_{4}-x_{24}$ & 0.69 & 21.76 \\
\hline$\xi_{1}-\chi_{5}$ & 0.73 & 22.83 & $\xi_{4}-X_{25}$ & 0.71 & 21.13 \\
\hline$\xi_{1}-x_{6}$ & 0.80 & 20.84 & $\xi_{4}-X_{26}$ & 0.67 & 22.00 \\
\hline$\xi_{1}-x_{7}$ & 0.70 & 16.43 & $\xi_{4}-x_{27}$ & 0.67 & 18.87 \\
\hline$\xi_{1}-x_{8}$ & 0.65 & 20.80 & $\xi_{5}-X_{28}$ & 0.85 & 18.89 \\
\hline$\xi_{1}-X_{9}$ & 0.71 & 20.80 & $\xi_{5}-X_{29}$ & 0.95 & 19.68 \\
\hline$\xi_{1}-X_{10}$ & 0.76 & 23.53 & $\xi_{5}-\xi_{1}$ & 0.51 & 14.65 \\
\hline$\xi_{1}-x_{11}$ & 0.63 & 19.05 & $\xi_{5}-\xi_{2}$ & 0.35 & 8.64 \\
\hline$\xi_{2}-X_{12}$ & 0.83 & 21.94 & $\xi_{5}-\xi_{3}$ & 0.40 & 9.92 \\
\hline$\xi_{2}-X_{13}$ & 0.81 & 23.68 & $\xi_{5}-\xi_{4}$ & 0.48 & 12.36 \\
\hline$\xi_{2}-X_{14}$ & 0.76 & 21.09 & $\xi_{4}-\xi_{1}$ & 0.70 & 27.93 \\
\hline$\xi_{2}-X_{15}$ & 0.78 & 20.86 & $\xi_{4}-\xi_{2}$ & 0.65 & 22.79 \\
\hline$\xi_{2}-X_{16}$ & 0.70 & 18.00 & $\xi_{4}-\xi_{3}$ & 0.55 & 16.11 \\
\hline$\xi_{2}-X_{17}$ & 0.70 & 18.08 & $\xi_{3}-\xi_{1}$ & 0.60 & 20.11 \\
\hline$\xi_{2}-X_{18}$ & 0.66 & 17.65 & $\xi_{3}-\xi_{2}$ & 0.60 & 19.72 \\
\hline$\xi_{3}-X_{19}$ & 0.81 & 20.63 & $\xi_{3}-X_{21}$ & 0.63 & 23.83 \\
\hline$\xi_{3}-X_{20}$ & 0.92 & 23.22 & & & \\
\hline
\end{tabular}

\subsection{Factor naming and explanation}

By integrating the meanings of several items related to some particular factor, five factors are respectively named as commitment/connection, attachment/attention, familiarity/awareness, trust/respect, and association/ recognition. There is a difference between the result of five dimensions and the above hypothesized twelve dimensions. Product, brand, promoters, and other consumers may mutually relate to consumers and three brand relationship natures may be interrelated to some extent. Thus, several related dimensions of twelve will be rearranged into five dimensions. In fact, five dimensions still come from relationship participants and natures. For example, commitment/connection is about the affection and conation given to brand and product; attachment/attention is about the conation given to promoter and the cognition and affection given to consumer; familiarity/awareness is about the cognition given to the cognition given to promoter and product; trust/respect is about the affection given to brand; and association/recognition is about the cognition given to brand. In order to reflect the meanings of all factors properly, the factors names are decided by the meanings of the related items.

Compared to the prior main research findings such as BRQ, the five factors have two superiors, more completed and more stable. First, five factors are 
stemmed from four relationship participants and natures and many items with the reference of some related literatures, which ensures the completion of factors. For example, trust and satisfaction from Blackston, BRQ from Fournier, eight indicators from Duncon and Moriarty are embodied in these five dimensions. Second, five factors are the result from empirical study, which ensures the stability of factors.

\subsection{Reliability and validity of the five-dimension structure}

Reliabilities of the study contain internal and external consistency. All Cronbach's $\alpha$ of five dimensions are all bigger than 0.75 , which means internal consistency is good (see Table 6). In order to test external consistency, sample size is adjusted. Through factor analyses of bigger sample size (1,362 samples) and smaller sample clusters (8 different clusters), the same five dimensions are achieved. Hence, the reliability of five dimensions is good.

Table 6 Internal consistency

\begin{tabular}{lcc}
\hline & Cronbach $\alpha$ & Quantity of items \\
\hline \multicolumn{1}{c}{ All factors } & 0.9352 & 29 \\
F1: commitment/connection & 0.9085 & 11 \\
F2: attachment/attention & 0.8546 & 7 \\
F3: familiarity/awareness & 0.7867 & 5 \\
F4: trust/respect & 0.8019 & 4 \\
F5: association/recognition & 0.7645 & 2 \\
\hline
\end{tabular}

Content validity is tested. As known from the above, good validity of the scale composed of twenty-nine items indicates that the scale can measure the condition of brand relationships in broad sense. Because five dimensions come from twenty-nine items, these dimensions also can reflect brand relationships in broad sense to a certain extent.

\section{Deduction of the brand relationship index model}

Five components in brand relationships structure in a broad sense are just the indicators needed in the evaluation of brand relationships in a broad sense and twenty-nine items are the measures of these indicators. The meaning of five indicators is shown as below. Indicator 1 is commitment/connection, which measures the extension of the consumer-brand relationships and the degree of fitting between consumers and brand; indicator 2 is attachment/attention, which measures the kindness between a consumer and other consumers of the brand 
and the consumer's intention to pay attention to promoter and brand; indicator 3 is familiarity/awareness, which measures consumer's knowledge of product and marketer's important attributes; indicator 4 is trust/respect, which measures the consumer's trust on marketer and the respects consumer received; indicator 5 is association/recognition, which measures the consumer's impression on brand logo or symbol.

There is no equality between the weights of items, so the indicator score should be the weighted sum of all items related to it. Obviously, it is not convenient to calculate the weights. The researcher contrasts weighed average to arithmetic mean. According to the result of Paired Samples T-Test, the difference between two methods is not significant ( $\mathrm{sig} .=0.00<0.01$ ). In order to make calculation easily, the method of arithmetic mean is selected to calculate the indicator score.

From theoretical point of view, five indicators as components of brand relationships can be used to evaluate brand relationships totally. Therefore, one factor should substitute for these five indicators. The hypothesis should be tested by a secondary order factor analysis. According to the calculation results by LISREL8.2, only one factor is achieved. The cumulative extraction sum of squared loadings is $58.315 \%$, which means one factor can substitute for five indicators for evaluation. Some fit indices of the model are that $\chi^{2} / \mathrm{df}=4.39$, $R M S E A=0.067, C F I=0.85, N N F I=0.83$, which indicate good degree of fitting. Therefore, five indicators will be substituted by one indicator. All $t$ values of path coefficients exceed 2, which prove the significance of path relationship between one second-order factor and five first-order factors. According to a weight approach named systematic effective weight (SEW), the bigger the coefficients are, the stronger the relationships are. The weights of five indicators will be achieved by the normalization of these coefficients.

By combining indicators system, weight, and integration, the score measuring the aggregate level of brand relationships in broad sense can be achieved. In order to describe relationship conditions under the frame of reference, we need a kind of relative values-index. The scope of index score is from 0 to 100 (see Formula 1). The higher index is, the more healthy relationship is. Besides the aggregate level of brand relationships, every indicator score can be calculated into index, which respectively mirrors various aspects of brand relationships. The former index is named as total index, and the latter one is named as branch index (see Formula 2).

$B R I=\frac{\left(\frac{e_{1}}{\sum_{x=1}^{5} e_{x}} \times \frac{\sum_{i=1}^{11} i_{i}}{11}+\frac{e_{2}}{\sum_{x=1}^{5} e_{x}} \times \frac{\sum_{i=12}^{7} i_{i}}{7}+\frac{e_{3}}{\sum_{x=1}^{5} e_{x}} \times \frac{\sum_{i=19}^{5} i_{i}}{5}+\frac{e_{4}}{\sum_{x=1}^{5} e_{x}} \times \frac{\sum_{i=24}^{4} i_{i}}{4}+\frac{e_{5}}{\sum_{x=1}^{5} e_{x}} \times \frac{\sum_{i=28}^{2} i_{i}}{2}-1\right)}{5-1} \times 100$ 


$$
B R I_{x}=\frac{\frac{\sum_{i=a}^{b} i_{i}}{b}-1}{5-1} \times 100
$$

In Formula 2 and 3,

$B R I$ - Brand relationships total index

$B R I_{x}$ - Brand relationships branch index $x$

1 - the lowest score of brand relationships

5 - the highest score of brand relationships

$x$ - the serial number of index, from 1 to 5

$e_{x}$-path coefficient between indicator $x$ and total indicator

$e_{1}$-path coefficient between indicator 1 (commitment/connection) and total indicator

$e_{2}$-path coefficient between indicator 2 (attachment/attention) and total indicator

$e_{3}$-path coefficient between indicator 3 (familiarity/awareness) and total indicator

$e_{4}$-path coefficient between indicator 4 (trust/respect) and total indicator

$e_{5}$-path coefficient between indicator 5 (association/recognition) and total indicator

$i_{i}$-item score

$i$ - serial number of index

$a$-initial serial number of item related to indicator, respectively $1,12,19,24$, 28

$b$-number of items related to indicator, respectively 11, 7, 5, 4, 2

\section{Validity test of the BRI model}

Does the BRI model really measure brand relationships strength? In other words, what about the validity of the model? The question is critical for deciding the value of the model. Perceived value and satisfaction are the basis of brand relationships, and intention to support the brand for a long time is the important representation of brand relationships (Grönroos, 2002). According to Grönroos’s view of point, three questions are designed to measure the model validity, which are "I am very satisfied with brand $X$ ”, "brand $X$ is a very excellent brand", and "I will support brand $X$ for a long time”. The three questions mirror total satisfaction, total attitude and relationship length. As shown by the calculative result, Pearson's correlation coefficients between brand relationships total index and the three variables are respectively $0.646,0.671$ and 0.647 , which means the correlation is significant (sig. $=0.00<0.01$, 2-tailed). 
In order to test the validity of BRI model, ten typical brands were chosen from the mobile phone industry, which are Motorola, Nokia, Samsung, Siemens, Alcatel, Bird, TCL, Kejian, Amoi, and Dbtel. There are differences between these ten brands in the origin of country, enterprise situation, and market performance. In order to contract BRIs, the samples of different brands should be similar. It is ensured by choosing college students as samples. Five hundred and fourteen valid samples from five universities are available. All item-total correlations exceed 0.4 and Cronbach's $\alpha$ of twenty-nine items exceeds 0.9644 , which means good reliability. The total and branch indices of $B R I$ of all mobile phone brands are calculated (see Table 7). If BRI is of high validity, it will reflect the possession of mobile phone to some extent. The result of calculation is that Pearson interrelationship coefficient is 0.837 ( sig. $=0.000<0.01$, 2-tailed), which means the validity of $B R I$ is good.

Table 7 Total relationship indices and branch relationship indices of 10 mobile brands

\begin{tabular}{lcccccccc}
\hline BRI ranking & Brand name & Sample & $B R I$ & $B R I_{1}$ & $B R I_{2}$ & $B_{2} I_{3}$ & $B^{2} I_{4}$ & $B_{5}$ \\
\hline 1 & Nokia & 52 & 62.27 & 67.70 & 51.55 & 51.54 & 67.43 & 74.33 \\
2 & Motorola & 54 & 58.11 & 52.06 & 49.97 & 49.72 & 63.95 & 76.62 \\
3 & Samsung & 52 & 51.29 & 51.67 & 46.39 & 43.37 & 57.93 & 57.93 \\
4 & Siemens & 53 & 50.57 & 47.53 & 46.06 & 42.55 & 58.99 & 58.79 \\
5 & Alcatel & 49 & 39.84 & 36.25 & 37.83 & 30.56 & 49.65 & 45.85 \\
6 & TCL & 52 & 39.61 & 33.52 & 34.51 & 35.00 & 48.38 & 47.84 \\
7 & Kejian & 48 & 38.65 & 33.97 & 36.40 & 33.96 & 49.80 & 39.84 \\
8 & Bird & 54 & 38.15 & 32.37 & 32.41 & 31.67 & 47.05 & 48.61 \\
9 & Amoi & 51 & 36.18 & 31.48 & 32.98 & 31.64 & 45.22 & 40.44 \\
10 & Dbtel & 49 & 25.39 & 24.61 & 27.87 & 17.24 & 36.48 & 20.91 \\
\hline
\end{tabular}

\section{Marketing applications of the BRI model}

First, BRI can be a convenient tool to measure the brand relationship strength comprehensively. Essentially, this research belongs to evaluation type in the field of applied theoretical research (Miller and Salkind, 2004). Therefore, the key application value of the model is to make brand managers grasp brand relationship quality through measuring it in time.

Second, BRI can be a new basis of market segmentation. Managers should provide different relationship marketing strategies for consumer clusters with different relationships. In order to manage relationship effectively, managers must know the relationship strength. However, the current segmentation methods are hardly to make sure relationship cluster because of the omission of measuring tool. The BRI model can solve the problem by mirroring the brand relationships conditions conveniently. 
Third, BRI can be a decision basis for consumers to make brand choice. Although almost all consumers prefer to the brands with good relationships with consumers, it is difficult for consumers to judge the condition of brand relationships according to brand awareness, market share or brand equity ranking. The reason is that these indicators can not completely reflect the real conditions of brand relationships. If government office or authoritative organization in market research issues a BRI ranking of some industries and brands based on the market data, consumers can make purchase decisions effectively and reliably. The ranking result will drive companies to make endeavor to develop their relationships with consumers.

Fourth, BRI is good to direct brand relationships management. Brand relationship index describes comprehensive conditions of brand relationships and BRI describes several aspects of brand relationships, which can refine brand relationships management. It is significant to analyze the changes of the indices from the perspectives of time series and competence gap. The analysis of time series can help manager pursue the development of brand relationships (Grönroos, 1994) and adjust brand management strategy. Whereas, the analysis of competence gap can help manager find the strength and weakness of brand relationships aspects and determine the direction to enhance competence.

\section{Discussion}

According to the definition of relationship, participant and nature are abstracted as relationship dimensions. Interpersonal relationship structure and brand identity subjects are respectively used as the basis of brand relationship nature and participant.

Based on nature and participant, the research constructs a hypothesis of broad brand relationship matrix. Through EFA and CFA, broad brand relationship indicator system comprising commitment/connection, attachment/attention, familiarity/awareness, trust/respect, and association/recognition is achieved. With the help of indicator weights resulting from the normalization of path coefficients, the BRI model is put forward. The model is easier to manipulate than value evaluation method and more reasonable than prior indicator evaluation method.

There are several limitations concerning sample size, sampling structure and industry choice in the research. In the future research, the researcher need retest the model by EFA and CFA with bigger sample size and better sampling structure. In addition, more brands can be evaluated by the BRI model in more industries. In order to facilitate the calculation, BRI software should be developed based on BRI model. Through the software, twenty-nine items data are input and one total index and five branch indices are output. 
Acknowledgements This work was supported by Guangdong Natural Science Foundation (project number: 05301010).

\section{References}

Aaker D A (1991). Managing Brand Equity. New York: Free Press

Aaker D A (1995). Building Strong Brands. New York: Free Press

Aaker J, Fournier S, Brasel S A (2001). Charting the development of consumer-brand relationships. Research Paper Series, Graduate School of Business Stanford University

Barnes J G (2000). Secrets of Customer Relationship Management: It’s All About How You Make Them Feel. New York: McGraw-Hill

Blackston M (1992). Observations: Building equity by managing the brand's relationships. Journal of Advertising Research, (32): 79-83.

Chen Zhengsui, Hong Shunqin (1999). Scale development of consuming goods brand equity based on customer. Zhongshan Management Review, 7(4): 1175-1199 (in Chinese)

Duncan T, Moriarty S (1997). Driving Brand Value. New York: McGraw-Hill

Fournier S M (1998). Consumer and their brands: Developing relationship theory in consumer research. Journal of Consumer Research, (24): 343-373

Griffin J (1995). Grasping Customer Heart: How to Cultivate and Maintain Loyal Customer. CA: Jossey-Bass, Inc.

Grönroos C (2000). Service Management and Marketing: A Customer Relationship Management Approach (2nd Edition). London: John Wiley \& Sons, Inc.

Hou Jietai, Wen Zhonglin, Cheng Zhijuan (2004). Structure Equation Model and Its Applications. Beijing: Education Science Press (in Chinese)

Huang Shengbin, Lu Taihong (2003). Localization research on brand personality dimensions. Nankai Management Review, (1): 4-9 (in Chinese)

Le Guo'an (2002). Current Chinese Interpersonal Relationships Research. Tianjin: Nankai University Press (in Chinese)

Lu Taihong (2002). Evaluation models and methods on brand equity. Sun Yat-Sen University Journal (Social Sciences), (3): 88-96 (in Chinese)

Lu Taihong, Zhou Zhimin (2003). Brand theories based on brand relationships: A research model and prospects. Business Economics and Administration, (2): 4-9 (in Chinese)

Keller K L (2001). Building customer-based brand equity. Marketing Management, (10): 14-19

Malhotra N K (1999). Marketing Research: An Applied Orientation (3rd Edition). NJ: Prentice Hall, Inc.

McAlexander J H, Schouten J W, Koenig H F (2002). Building brand community. Journal of Marketing, (66): 38-54

Olsen S O (2002). Comparative evaluation and the relationship between quality, satisfaction, and repurchase loyalty. Journal of the Academy of Marketing Science, (30): 240-249

Qiu Dong (1991). Systematic Analysis of Multi-Indicator Evaluation Method. Beijing: China Statistic Press (in Chinese)

Rust R T, Zeithaml, V A, Lemon K N (2000). Driving Customer Equity: How Customer Lifetime Value Is Reshaping Corporate Strategy. New York: Free Press

Sawhney M, Zabin J (2002). Managing and measuring relational equity in the network economy. Journal of the Academy of Marketing Science, (30): 313-332 
Shi Guicheng, Wang Yonggui, Xin Jingang, Yu Bin (2005). Relationship strength: Scale development and construct validation. Nankai Management Review (in Chinese), (3): 74-82

Shi Ronghua (1989). Modern Social Psychology. Shanghai: East China Normal University Press (in Chinese)

Sirdeshmukh D, Singh J, Sabol B (2002). Consumer trust, value, and loyalty in relational exchanges. Journal of Marketing, (66): 15-37

Webster F E (2000). Jr. Understanding the relationships among brands, consumers, and resellers. Journal of the Academy of Marketing Science, (28): 17-23

Yoo C B, Naveen D (2001). Developing and validating a multidimensional consumer-based brand equity scale. Journal of Business Research, (52): 1-14

Zhang Zhiguang (1996). Social Psychology. Beijing: People Education Press (in Chinese)

Zheng Quanquan, Yu Guoliang (1999). Interpersonal Relationships Psychology. Beijing: People Education Press (in Chinese)

Zhou Zhimin (2005). Research scope, perspectives and prospects of brand relationship evaluation. Foreign Economics \& Management, 1(1): 34-40 (in Chinese) 


\section{Appendix}

Broad brand relationships scale

1. I would like to recommend brand $X$ to my friends.

2. Image of brand $X$ is fit for my taste.

3. In product $Y$, no other brands can replace brand $X$ in my heart.

4. Image of brand $X$ fits my current lifestyle.

5. If I buy product $Y$ next time, I would like to buy brand $X$ again.

6. If brand $X$ is out of stock, I will go to another store to look for it instead of buying other brands.

7. I think highly of the prospect of brand $X$.

8. Although the price of brand $X$ is a little bit higher than other brands, I would like to choose it.

9. I will not regret for choosing brand $X$.

10. I would like to buy other products of brand $X$.

11. The product of brand $X$ satisfies my request for category $Y$ very well.

12. I pay attention to the news about company $X$.

13. I would like to visit the website of company $X$.

14. I would like to join the brand $X$ club to communicate with more customers of brand $X$.

15. I know the requirement of typical customers of brand $X$ for product $Y$.

16. The communication with brand $X$ customers makes me feel intimate.

17. I would like to help brand $X$ clients rather than other brands clients.

18. I would like to make friends with brand $X$ customers rather than other brands customers.

19. I know the differences of product attributes (such as function, appearance, capability) between brand $X$ and other brands.

20. I know the product line of brand $X$.

21. I know the business scope of company $X$.

22. I know the current prices of main brand $X$ products.

23. I know the development history of company $X$.

24. I think that company $X$ is familiar with the customers requirement for product $Y$.

25. I think that company $X$ will deal with the feedback from customers.

26. I believe that company $X$ will respect the customers' benefit.

27. I think that company $X$ commitment to customers is credible.

28. I can recognize brand $X$ only through its logo or advertising.

29. I I can associate its advertising or logo with brand $X$ 's name. 